\title{
Preliminary Results from an Investigation into Nanostructured Nuclear Radiation Detectors for Non-Proliferation Applications
}

Paul Guss ${ }^{a}$, Ronald Guise ${ }^{a}$, Ding Yuan ${ }^{b}$, and Sanjoy Mukhopadhyayc August 12-16, 2012

${ }^{a}$ Remote Sensing Laboratory-Nellis, P.O. Box 98521, M/S RSL-48, Las Vegas, NV 89193-8521,

${ }^{b}$ National Security Technologies-LLC-Los Alamos Operations, P.O. Box 809, M/S LAO/C320, Los Alamos, NM 87544-0809,

${ }^{c}$ Remote Sensing Laboratory-Andrews, P.O. Box 380 Suitland, MD 20752,

This work was done by National Security Technologies, LLC, under Contract No. DE-AC52-06NA25946 with the U.S. Department of Energy and supported by the Site-Directed Research and Development Program. 
The principle is that thanocrystals, crystals 2 to $5 \mathrm{~nm}$ in diameter, of certain inorganic scintillator materials can capture most of the energy from $V$ 's, thus offering nearly the performance of single large crystals, if packed densely enough in plastic. The resulting mixture also has the desirable features of plastic. The crystals are mixed in a modified polystyrene plastic, a scintillator material, so it increases the amount of energy converted to a detectable signal.

\begin{tabular}{|c|c|c|}
\hline Property & Crystal Detector & Nanostructured Detector \\
\hline Cost & $\$ 300 / c c$ & $\$ 1 / \mathrm{cc}$ \\
\hline Configuration & Fixed solid crystal & $\begin{array}{l}\text { Plastic; May be formed into large } \\
\text { sheets to increase sensitivity }\end{array}$ \\
\hline Temperature & $\begin{array}{l}\text { Ambient for Low resolution crystals; } \\
\text { Low for High resolution crystals }\end{array}$ & Ambient \\
\hline Photoluminescence & 2-120 K-photons/Mev [300-530 nm] & $\sim 70 \mathrm{~K}$-photons $/ \mathrm{Mev}[397-782 \mathrm{~nm}]$ \\
\hline Resolution & $\begin{array}{l}<1 \% \text { Low Temp; } 2-8 \% \text { Ambient } \\
\text { Temp for }{ }^{137} \mathrm{Cs}(662 \mathrm{keV})\end{array}$ & $\begin{array}{l}15 \% \text { achieved for } \\
{ }^{241} \mathrm{Am}(60 \mathrm{keV})\end{array}$ \\
\hline Efficiency & $\begin{array}{l}\text { PMTs suffer from low quantum } \\
\text { efficiency }(1-10 \%)\end{array}$ & $<60 \%$ \\
\hline
\end{tabular}




\section{Motivation}

1. Economics - Nanoparticle detectors offer the possibility of an economical detection system, with the promise of high sensitivity.

2. Efficiency - Nanoparticle detectors offer the possibility of achieving high quantum efficiencies and senstivity.

3. Energy Range - Nanoparticle detectors may even offer the possibility of broader energy spectral ranges.

\section{Goal}

To demonstrate the possibility of measuring both low-energy $\mathrm{X}$-rays and relatively high-energy gamma rays simultaneously using the nano-structured nuclear radiation detectors. 


\section{Technical Accomplishments - List of Detectors}

\begin{tabular}{|c|c|c|c|c|c|}
\hline \multirow[b]{2}{*}{ Figure } & \multicolumn{2}{|c|}{ Detector } & \multicolumn{2}{|c|}{ Properties } & \multirow{2}{*}{ Comment } \\
\hline & Nanoparticle & Type & Volume & Concentration & \\
\hline Figure 1 & CdSe/ZnS & Core Shell & $1 \mathrm{cc}$ & $1.40 \%$ & epoxide-amine polymer \\
\hline Figure 2 & CdSe/ZnS & Core Shell & $1 \mathrm{cc}$ & $2.80 \%$ & epoxide-amine polymer \\
\hline Figure 3 & CdSe:S & Quantum Dot & $1 \mathrm{cc}$ & $0.20 \%$ & epoxide-amine polymer \\
\hline Figure 4 & CdTe/ZnS & Core Shell & $1 \mathrm{cc}$ & $0.01 \%$ & \\
\hline Figure 5 & CdTe/ZnS & Core Shell & $1 \mathrm{cc}$ & $0.05 \%$ & \\
\hline Figure 6 & CdTe/ZnS & Core Shell & $1 \mathrm{cc}$ & $0.11 \%$ & \\
\hline Figure 7 & CdTe/ZnS & Core Shell & $1 \mathrm{cc}$ & $0.43 \%$ & \\
\hline Figure 8 & CdTe/ZnS & Core Shell & $1 \mathrm{cc}$ & $0.90 \%$ & \\
\hline Figure 9 & CdTe/ZnS & Core Shell & $1 \mathrm{cc}$ & $2 \%$ & \\
\hline Figure 10 & ZnSe:Mn & Quantum Dot & $1 \mathrm{cc}$ & $1 \%$ & polystyrene matrix \\
\hline Figure 11 & ZnSe:Mn & Quantum Dot & $1 \mathrm{cc}$ & $2 \%$ & polystyrene matrix \\
\hline Figure 12 & ZnSe:Mn & Quantum Dot & $1 \mathrm{cc}$ & $5 \%$ & polystyrene matrix \\
\hline Figure 13 & D1 & Core Shell & $<1 \mathrm{cc}$ & $0.90 \%$ & Surfactant \\
\hline Figure 14 & D2 & Core Shell & $<1 \mathrm{cc}$ & $0.43 \%$ & Surfactant \\
\hline Figure 15 & D3 & Core Shell & $<1 \mathrm{cc}$ & $0.11 \%$ & Surfactant \\
\hline Figure 16 & D4 & Core Shell & $<1 \mathrm{cc}$ & $0.05 \%$ & Surfactant \\
\hline Figure 17 & D5 & Core Shell & $<1 \mathrm{cc}$ & $0.01 \%$ & Surfactant \\
\hline Figure 18 & D6 & Core Shell & $<1 \mathrm{cc}$ & $0.90 \%$ & Surfactant \\
\hline & BC400 & Plastic & $<1 \mathrm{cc}$ & & Surfactant \\
\hline
\end{tabular}




\section{Technical Accomplishments - List of Detectors}

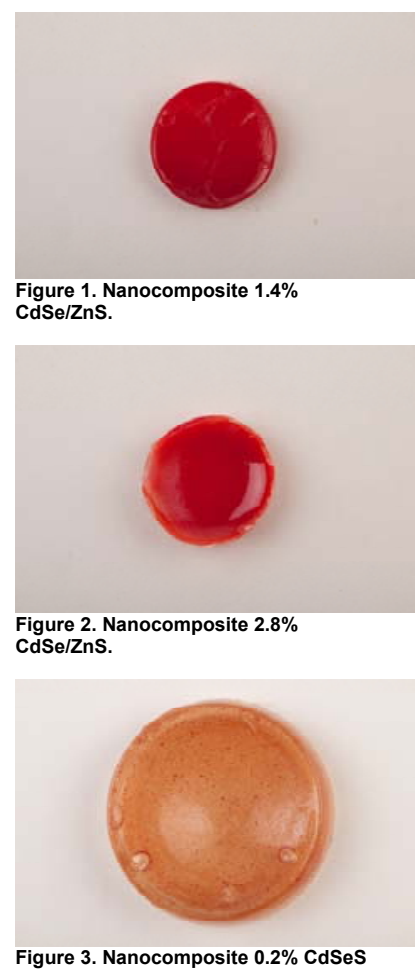

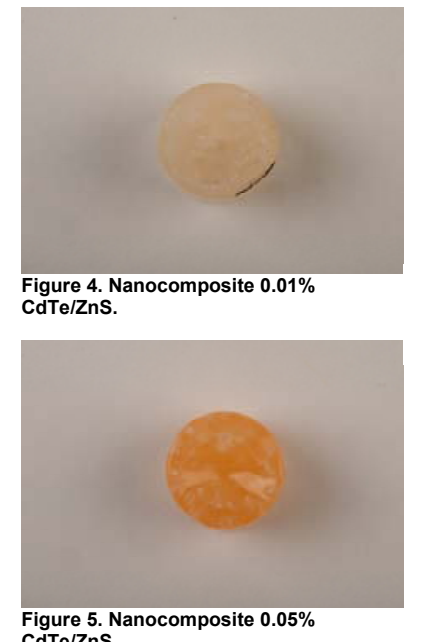

CdTe/ZnS.

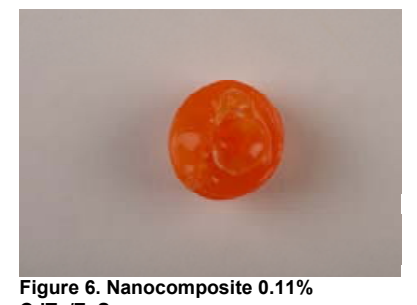

Figure 6. Nang
CdTe/Zns.
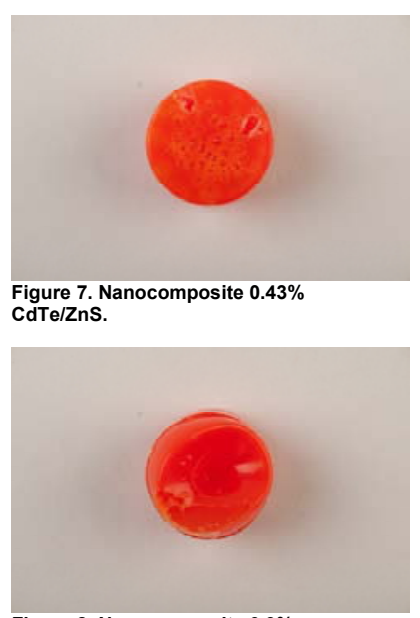

Figure 8. Nanocomposite $0.9 \%$ CdTe/ZnS.

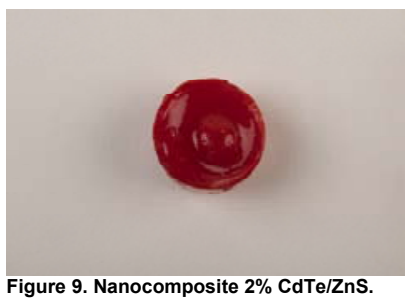

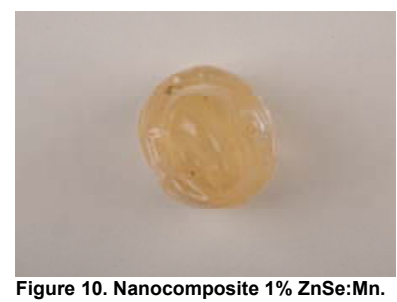

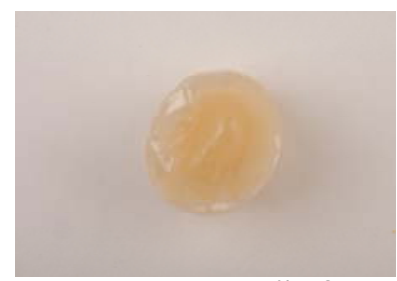

Figure 11. Nanocomposite $2 \% \mathrm{ZnSe}: \mathrm{Mn}$.

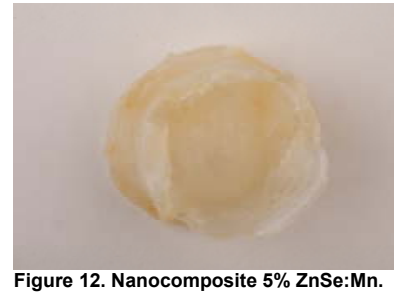

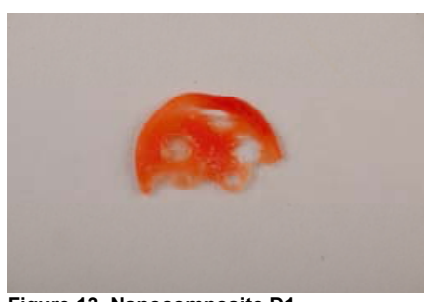

Figure 13. Nanocomposite D1

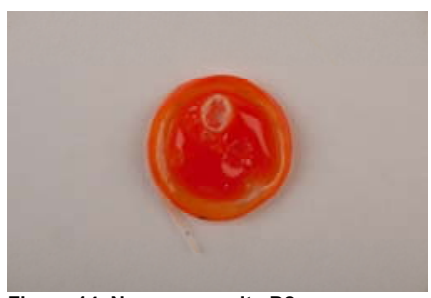

Figure 14. Nanocomposite D2.

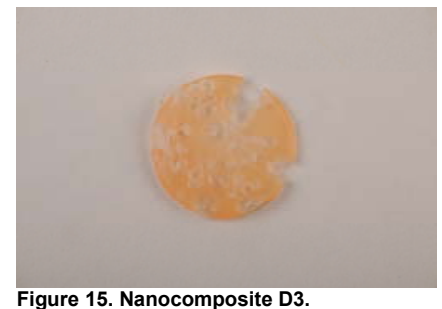

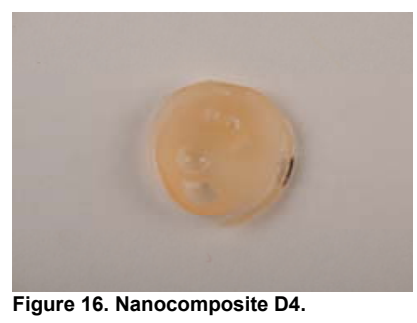

Figure 16. Nanocomposite D4.

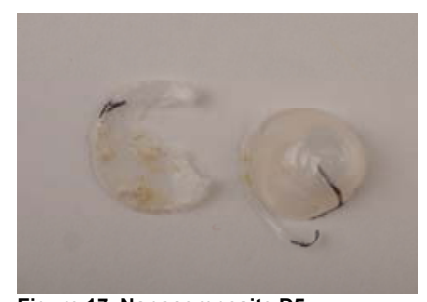

Figure 17. Nanocomposite D5.

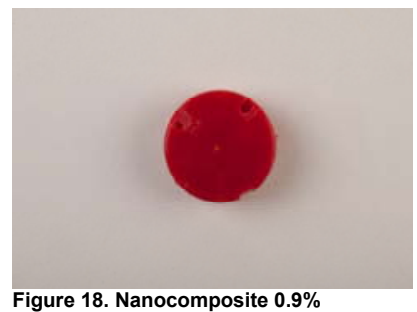
Figure 18. Nanocomposite $0.9 \%$
CdTe/ZnS surfactant. 


\section{Technical Accomplishments-Solid Nanoparticle Detector}

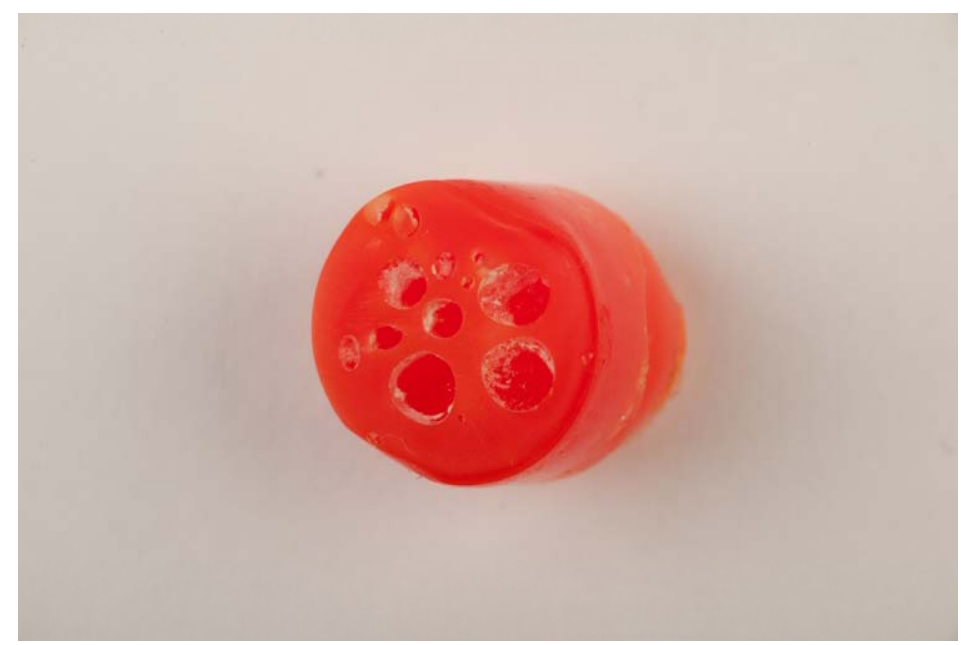

The $0.9 \% \mathrm{CdTe} / \mathrm{ZnS}$ nanocomposite detector is typically approximately $1 \mathrm{~cm}$ in diameter and $1 \mathrm{~cm}$ in length. It is not well polished. This small size geometry must be fit onto the $3 / 4$ " photomultiplier tube (PMT) with an excellent light coupling and placed inside a light-tight enclosure. 


\section{Technical Accomplishments- Solid Nanoparticle Detector Mount}

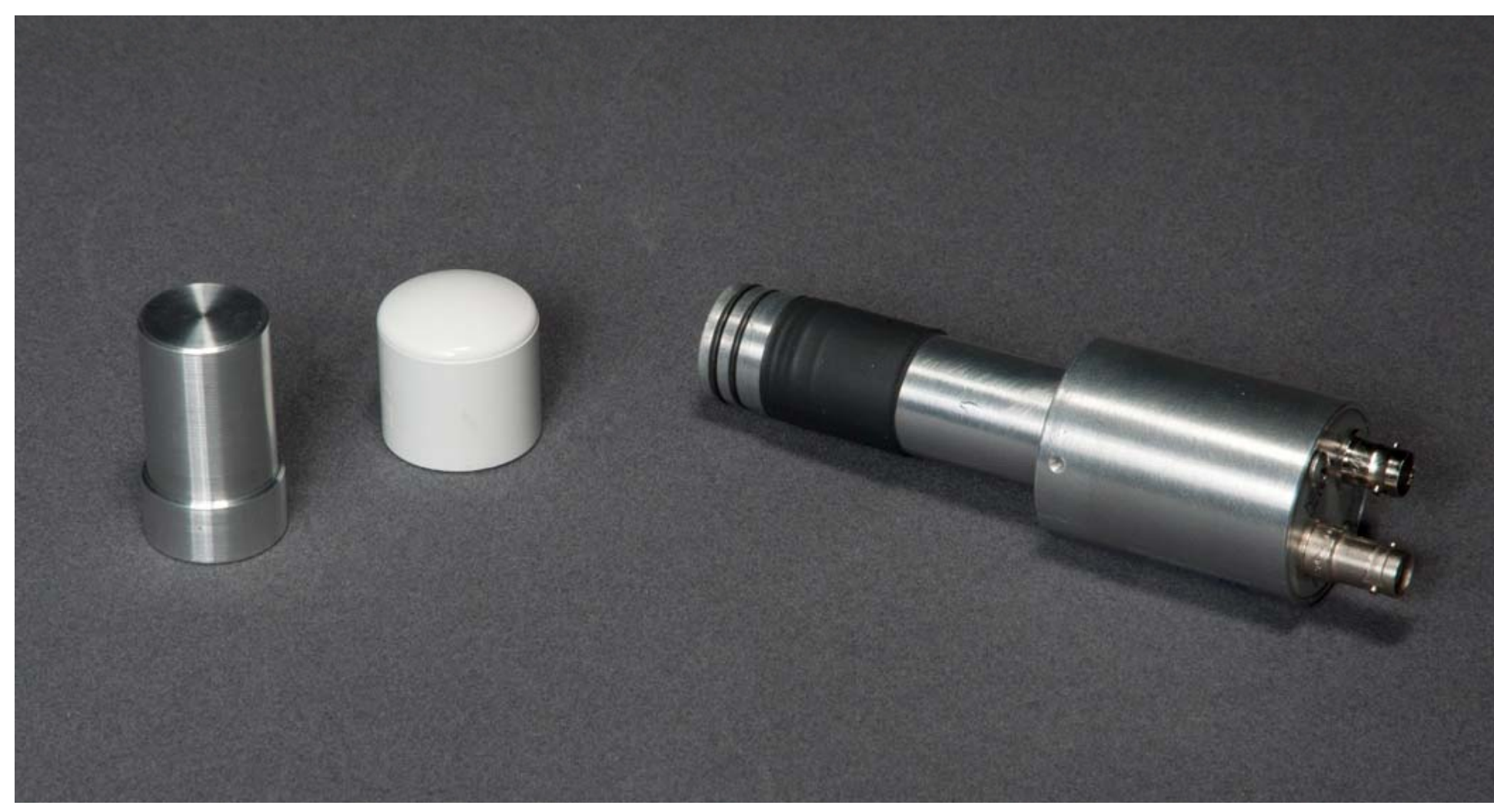

Aluminum detector mount is shown on left. The outer protective cap is shown in the middle. Photomultiplier tube is shown on the right. 


\section{Technical Accomplishments- Solid Nanoparticle Detector Mount}
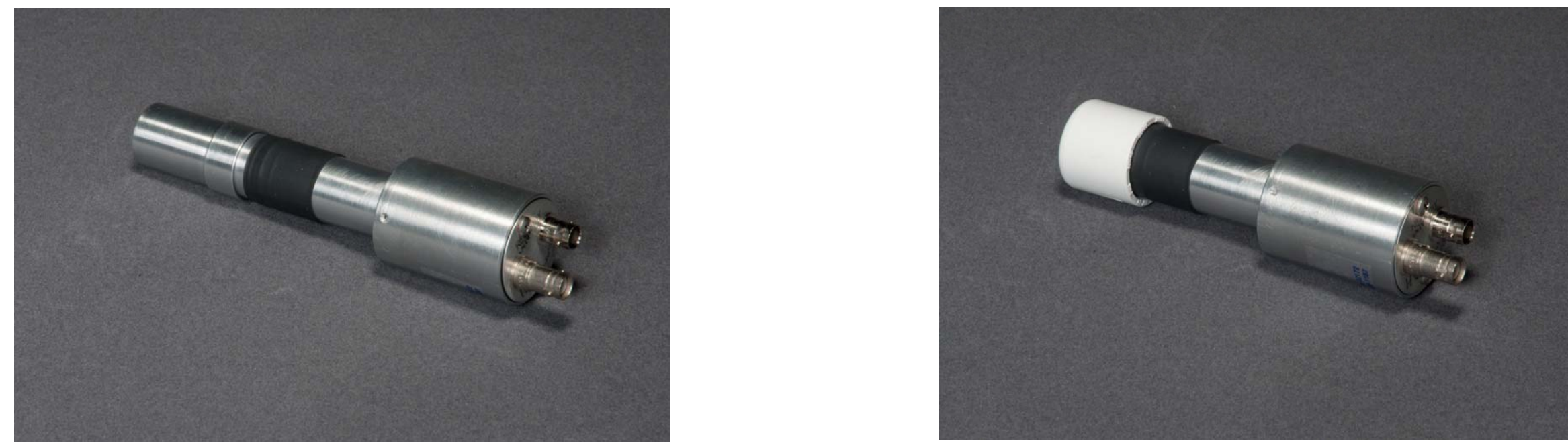

Photomultiplier tube with inner cap assembled is shown on left. Full assembly has the detector seated inside the inner cap, which is coupled by optical grease to the photomultiplier tube, and has the outer protective cap cover inserted over the inner cap containing the detector, as is shown on the right. 


\section{Technical Accomplishments}

- Stepped through plan for data acquisition

- Definitely determined an energy correlation to the spectra for different types of nanoparticle detectors and different concentrations of nanoparticle

- Nano-issues appeared with MCNPX

- Ran into unexpected results with several surface roughness case studies 


\section{Technical Accomplishments - BC400}

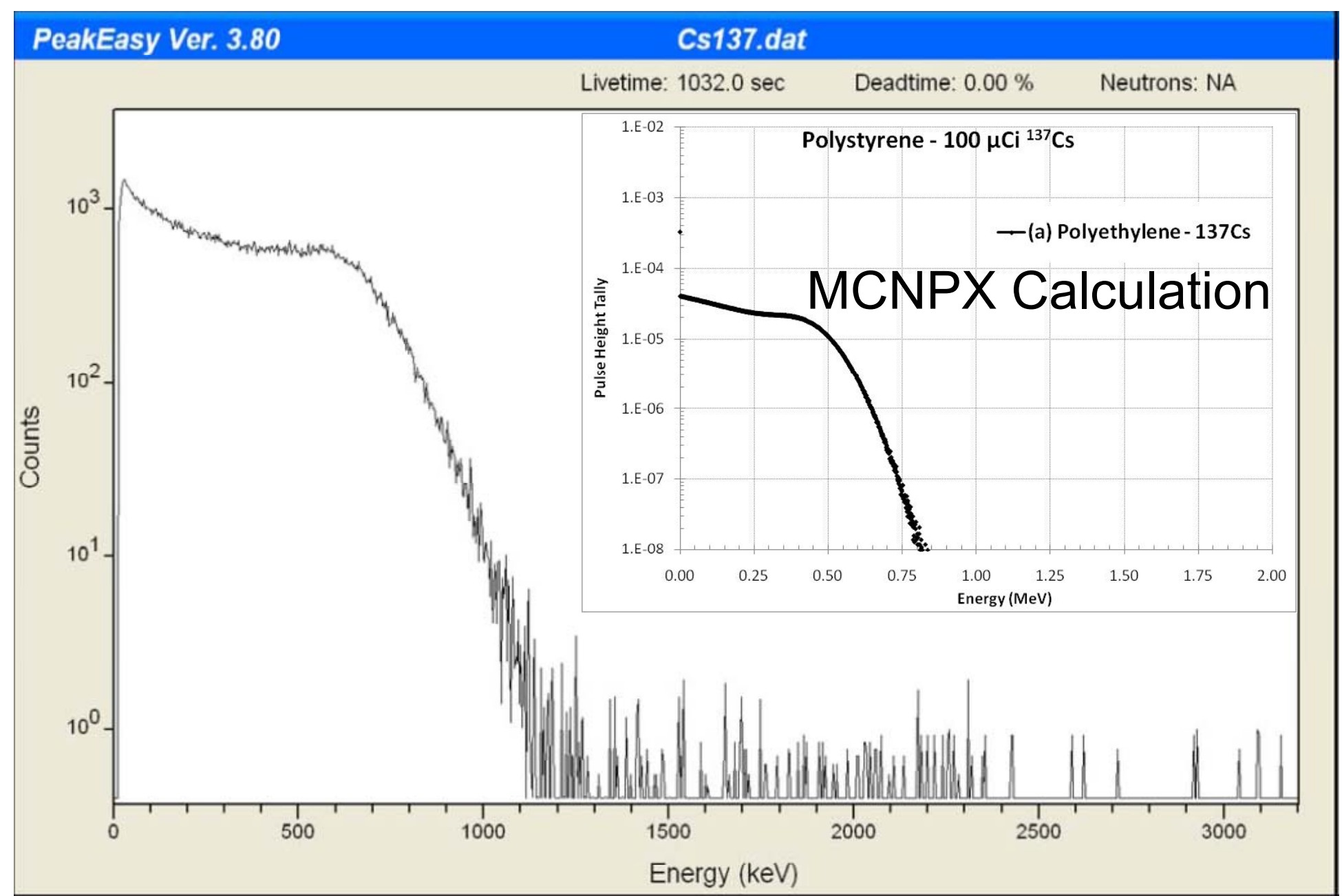

This is a ${ }^{137} \mathrm{Cs}$ spectrum (with background subtraction) acquired with a plastic BC400,12.5 mm diameter by $19 \mathrm{~mm}$ long detector using the new detector assembly. Inset: MCNPX calculation of simulated spectrum is shown. 
${ }^{241} \mathrm{Am},{ }^{137} \mathrm{Cs},{ }^{60} \mathrm{Co}$, and the Background Spectra Subtracted

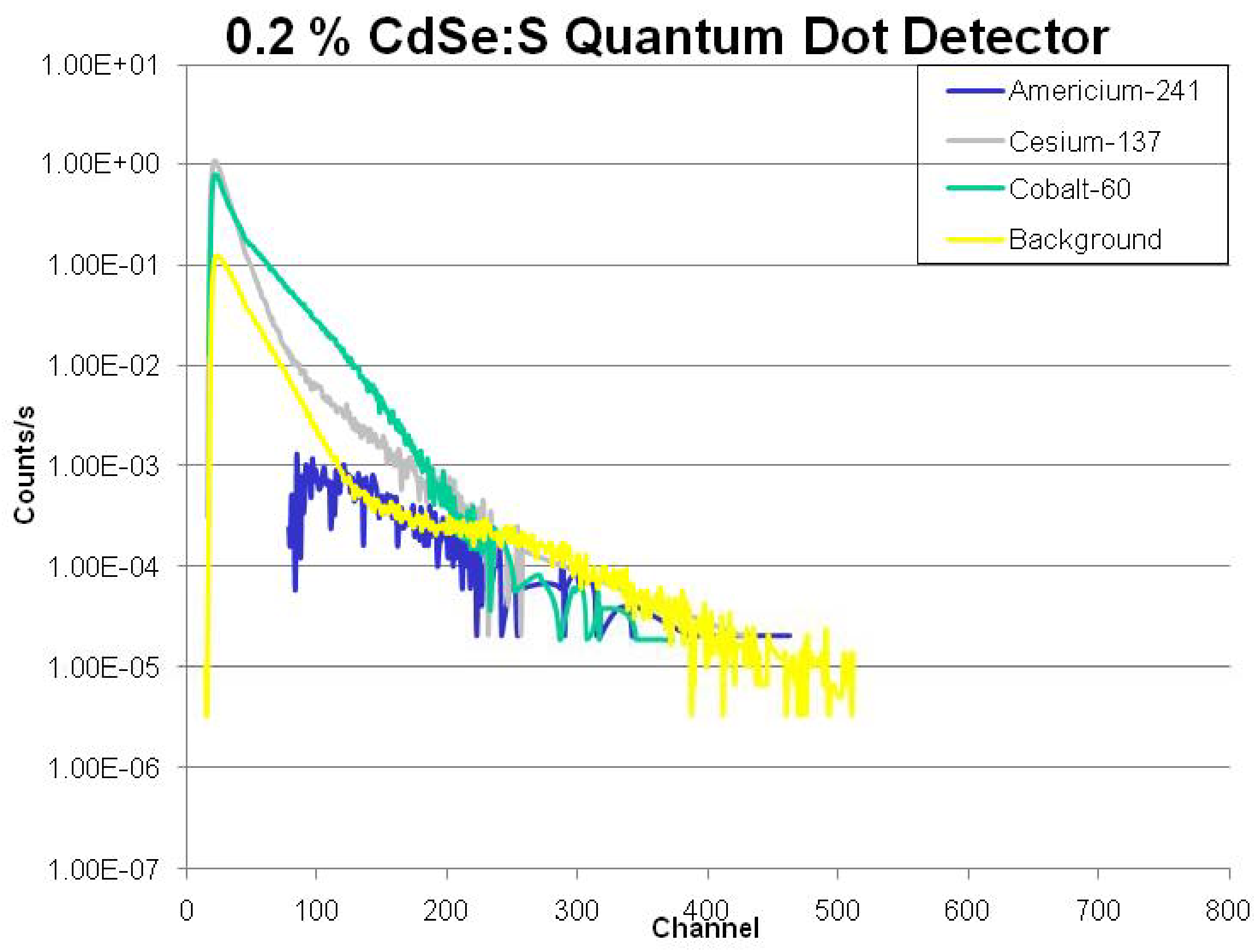




\section{Technical Accomplishments - 2.8\% CdSe/ZnS}

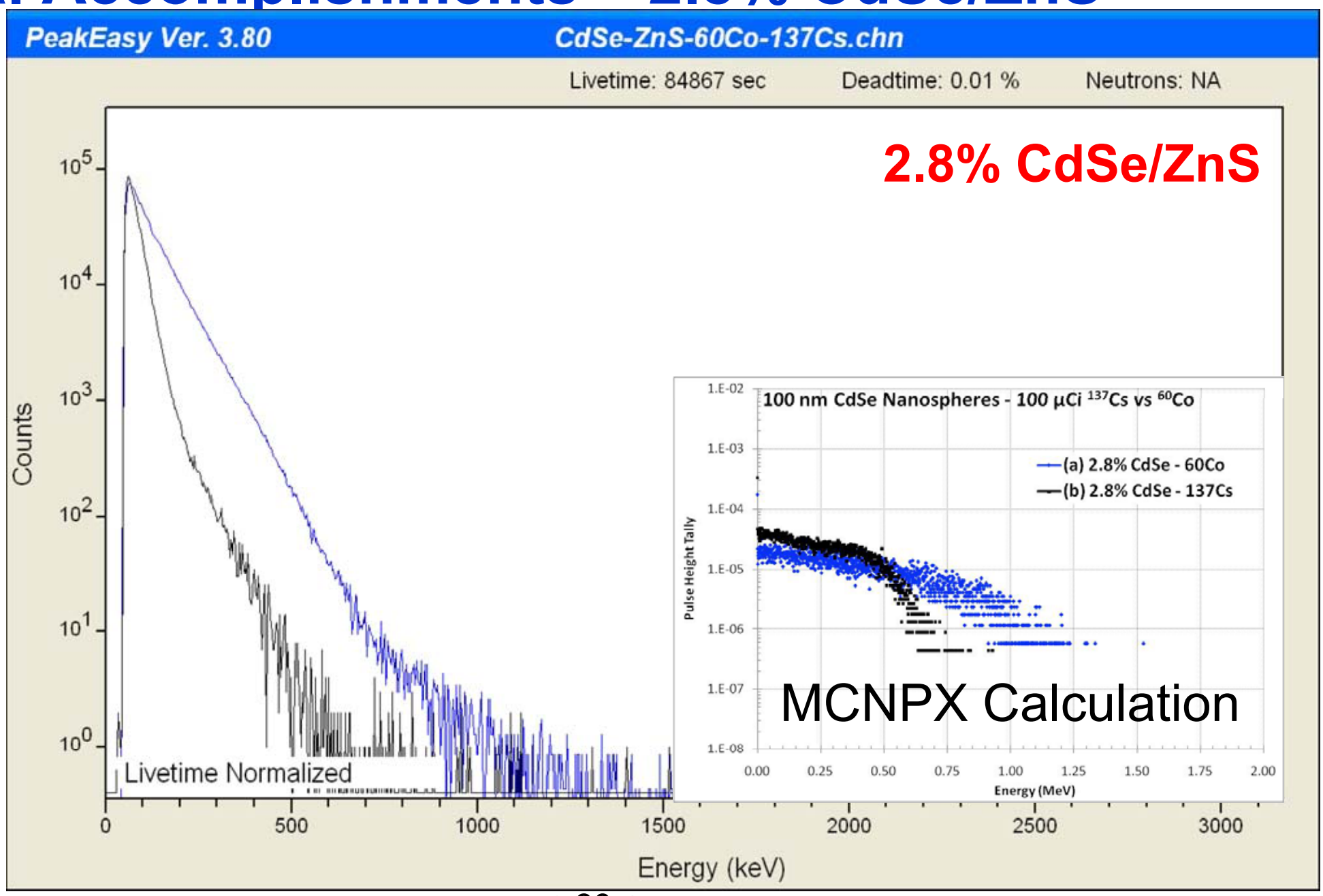

Background-subtracted spectrum of ${ }^{60} \mathrm{Co}$ source with both 1173- and $1332-\mathrm{kev}$ $\mathrm{Y}$ lines (blue) and of ${ }^{137} \mathrm{Cs}$ with 662-kev $\mathrm{y}$ line (black) taken with detector 2 , the $2.8 \% \mathrm{CdSe} / \mathrm{ZnS}$ core shell nanoparticle detector. Inset: MCNPX calculation of simulated spectra is shown. 


\section{Technical Accomplishments - 2.8\% CdSe/ZnS}

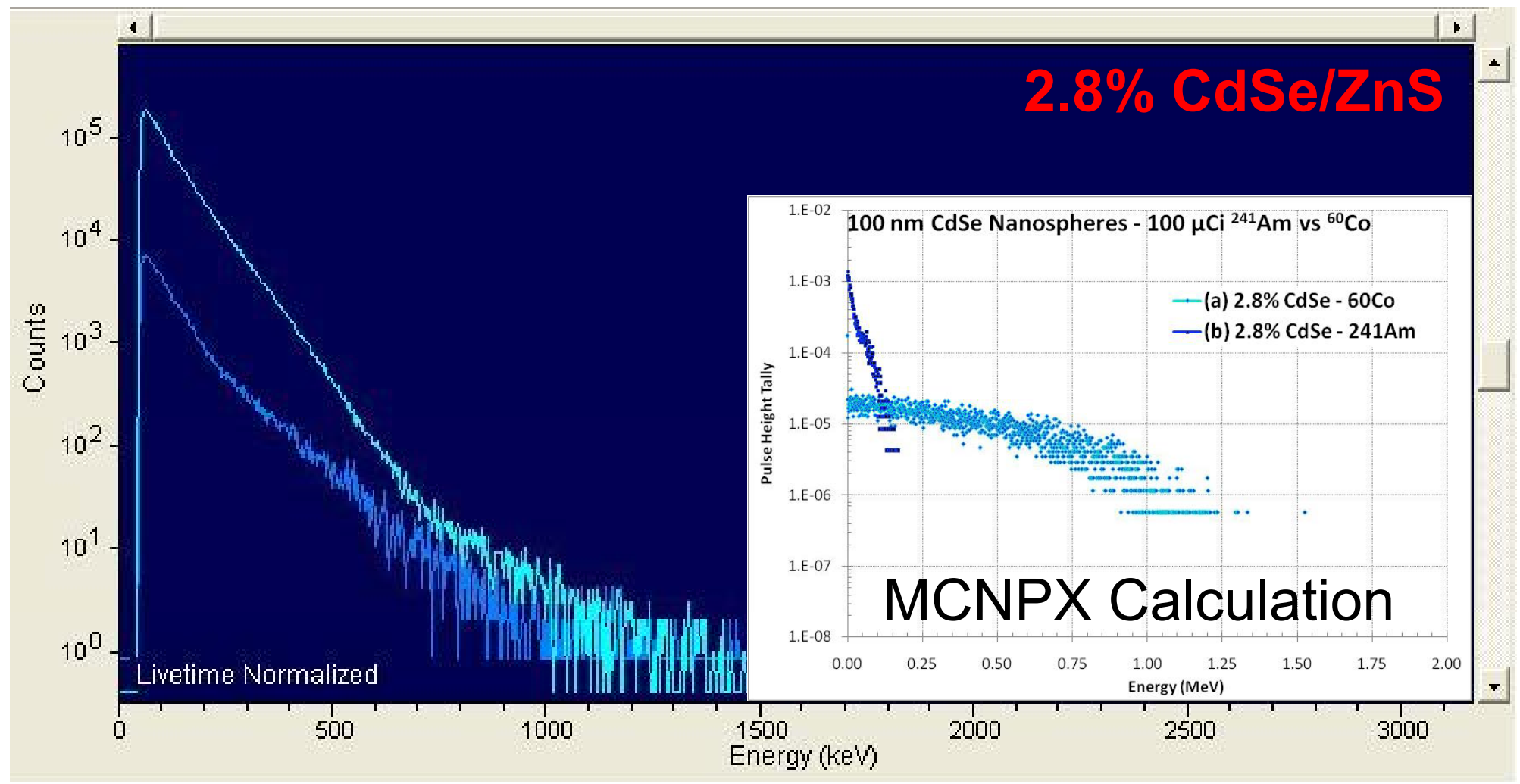

Raw spectra of ${ }^{60} \mathrm{Co}$ source with both 1173- and 1332kev $\mathrm{y}$ lines (aqua) and of ${ }^{241} \mathrm{Am}$ with 60-kev $\mathrm{y}$ line (blue) taken with $2.8 \% \mathrm{CdSe} / \mathrm{ZnS}$ core shell nanoparticle detector. 

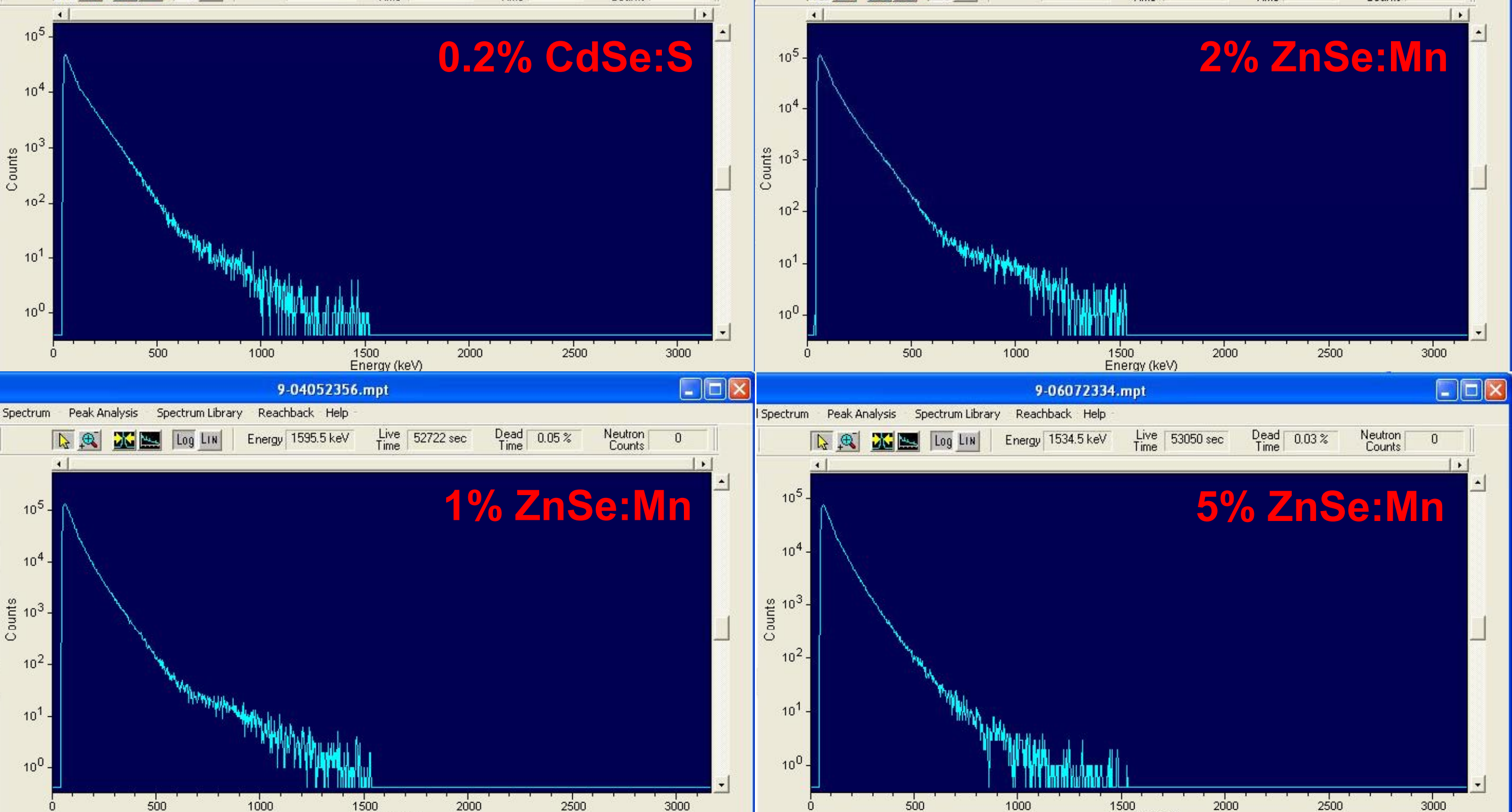

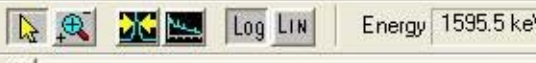

$$
\text { (5pe }
$$

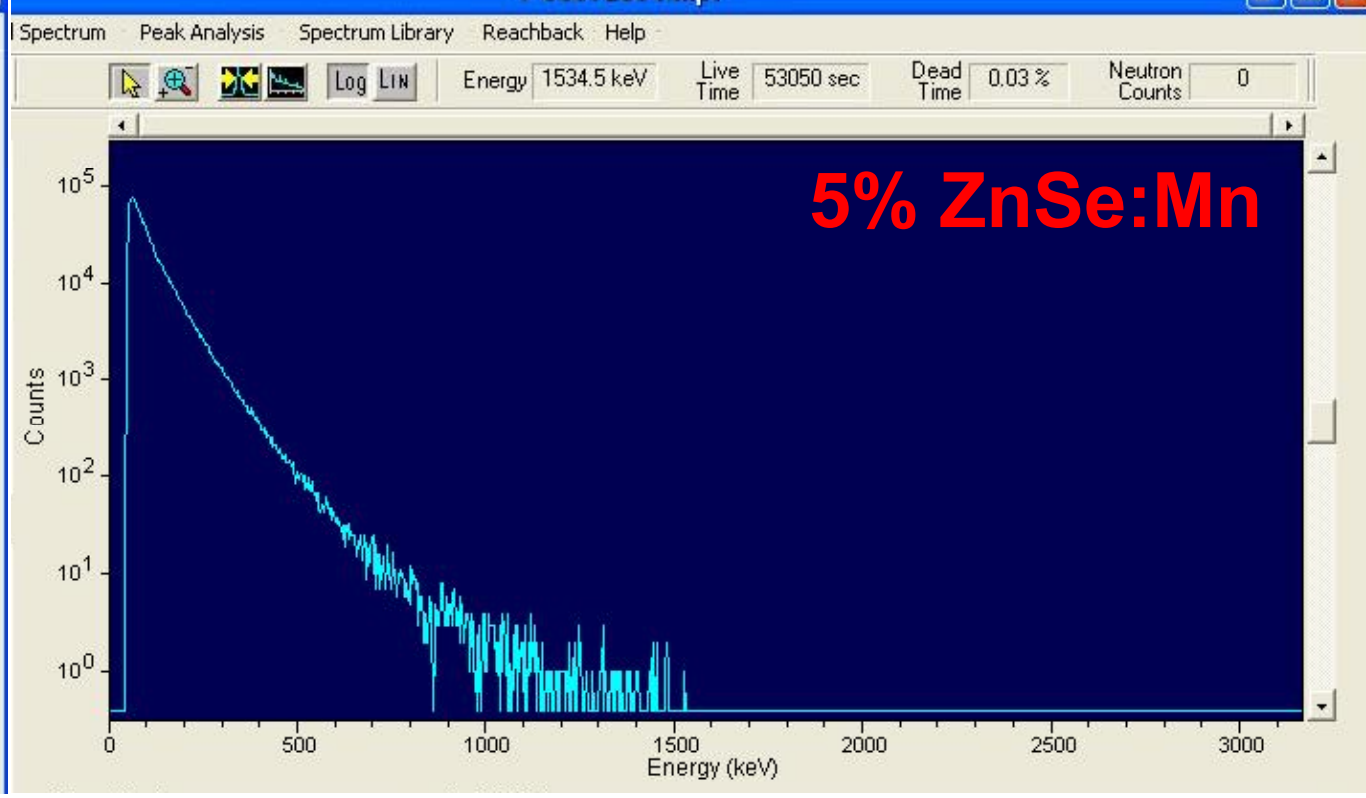

9.06072334.mp

Spectra of ${ }^{60} \mathrm{Co}$ source taken with $0.2 \%$ CdSe:S and $1 \%, 2 \%$, and $5 \%$ ZnSe:Mn quantum dot nanoparticle detectors. 


\section{Geometry for the MCNPX calculation of spectrum of ${ }^{137} \mathrm{Cs}$ source (with 662-kev y line) taken with a CdSe nanoparticle detector, with $8 \%$ of the mass composed of CdSe nanoparticles.}

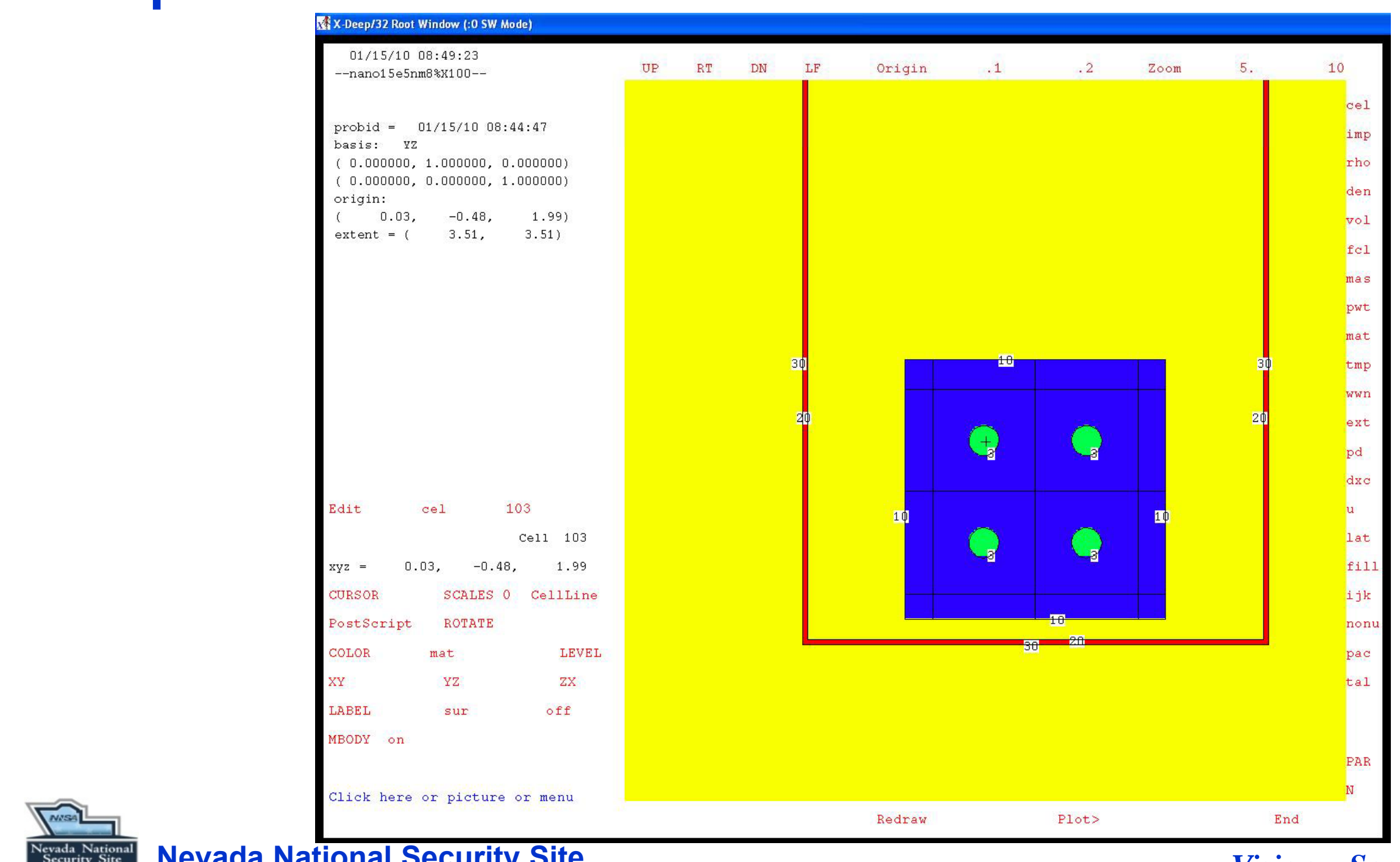


Geometry for the MCNPX calculation for detector with 1-mm CdSe millispheres. In this case, millispheres are nearly to scale, and correctly project the relative abundance of material of CdSe to compose $2.8 \%$ of the mass of the detector

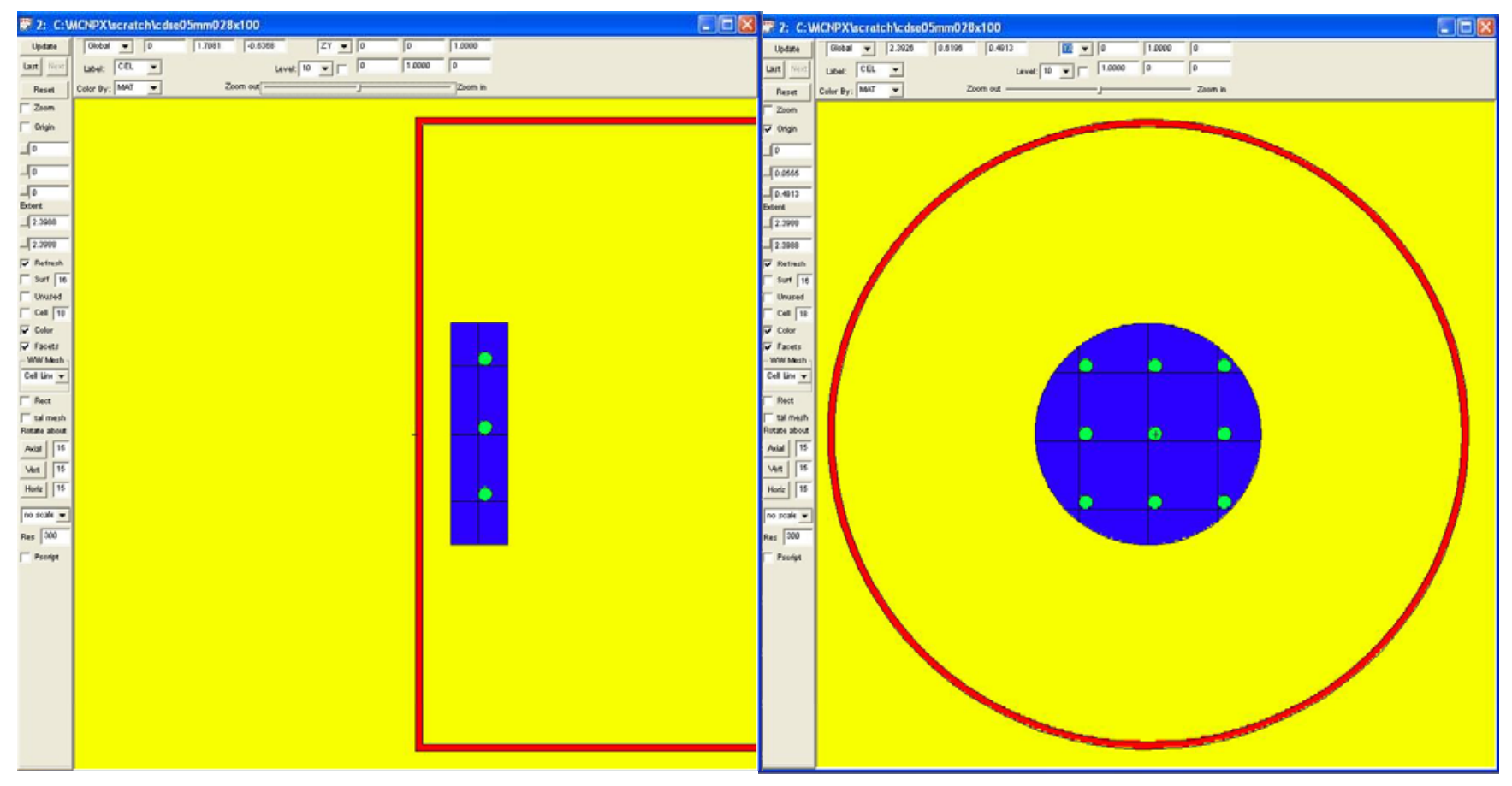




\section{MCNPX calculation of spectrum of ${ }^{137} \mathrm{Cs}$ source (with 662-kev Y line) taken with detector 2 , the $2.8 \% \mathrm{CdSe} / \mathrm{ZnS}$ core shell nanoparticle detector with a polystyrene matrix, with $100 \mathrm{~nm}$ CdSe nanospheres, compared to a background spectrum}

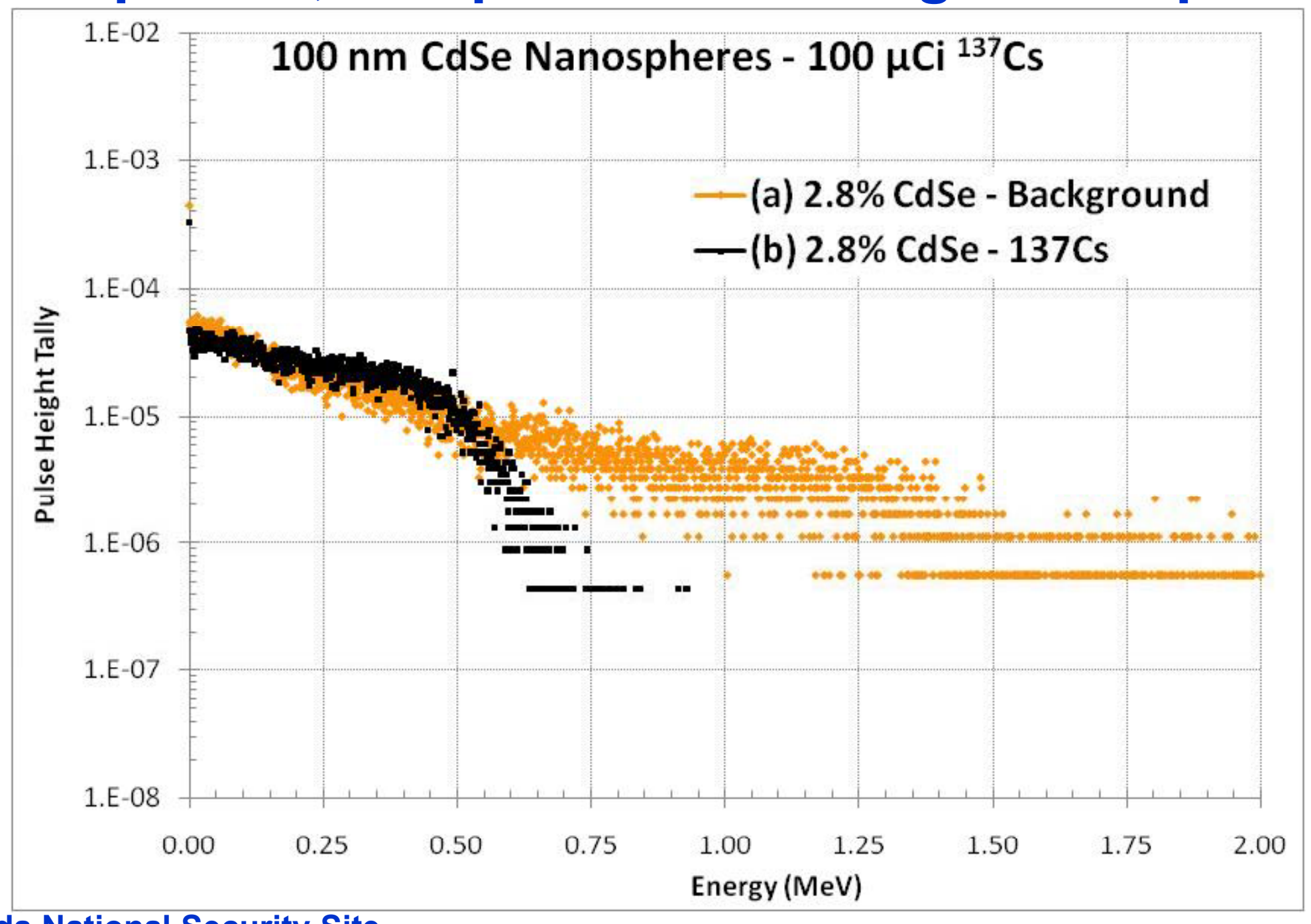




\section{MCNPX Calculation versus Data}
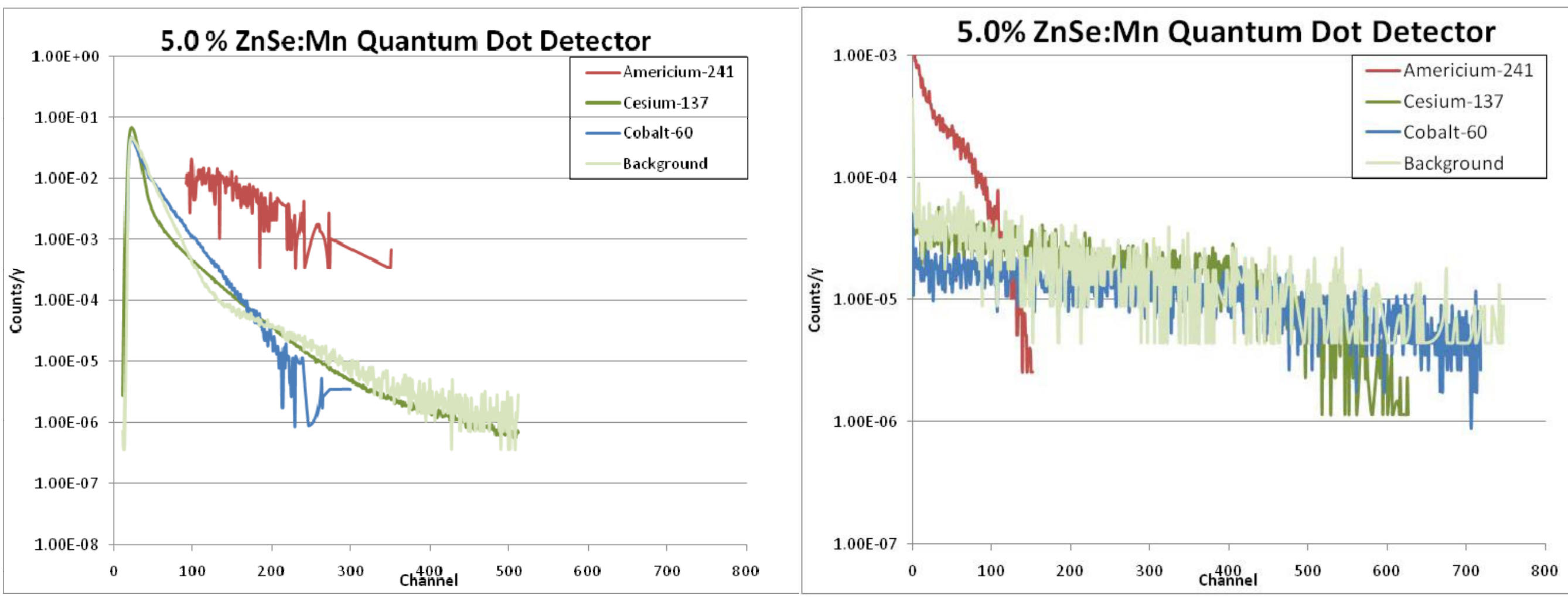

\section{Data}

\section{MCNPX}




\section{${ }^{241} \mathrm{Am},{ }^{137} \mathrm{Cs},{ }^{60} \mathrm{Co}$, and the Background Spectra Subtracted}
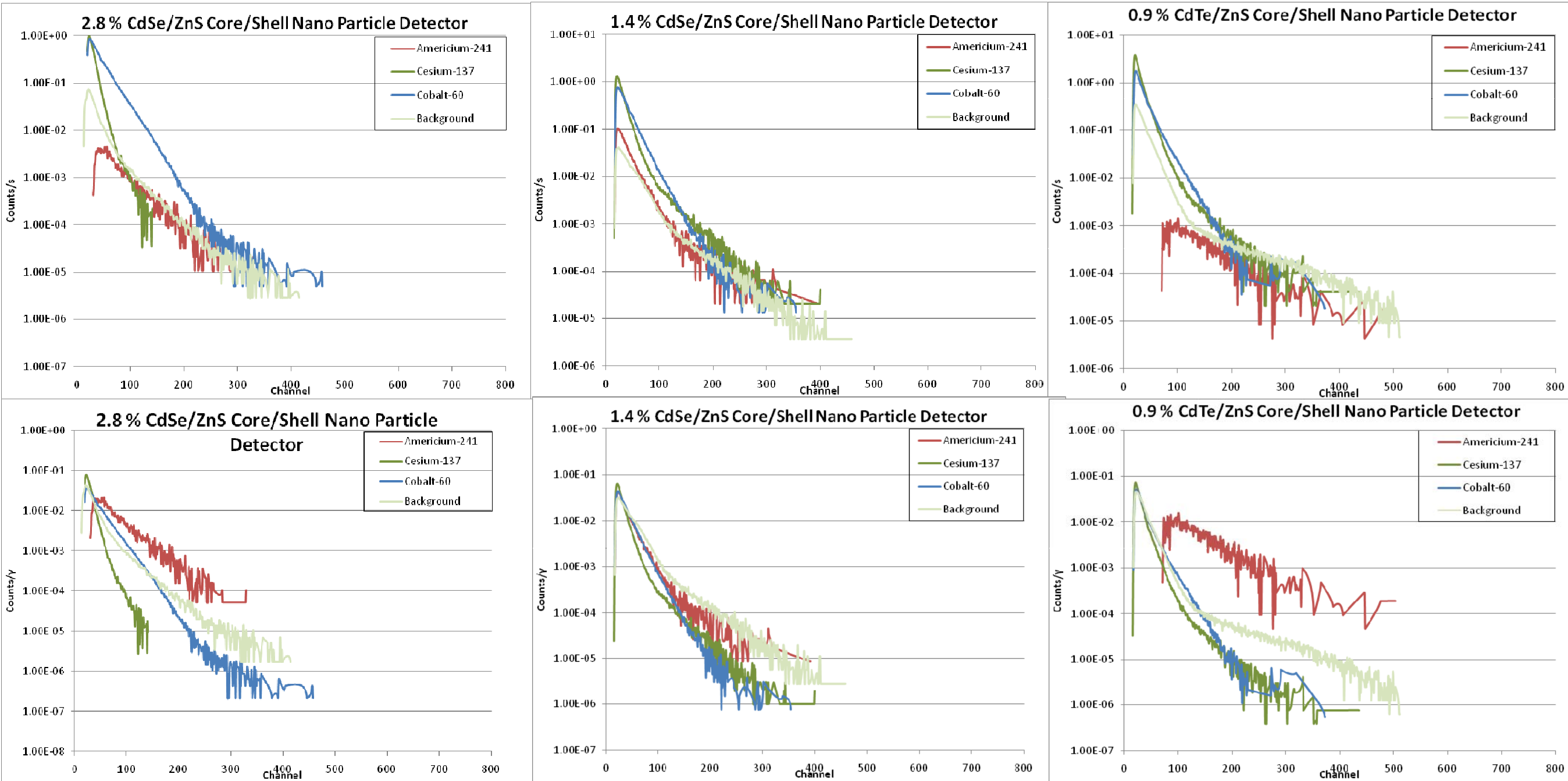

\section{Top: Count Rate (Counts/s); Bottom: Probability Spectrum (Counts/y)}




\section{Results}

- Solid Nanoparticle detector
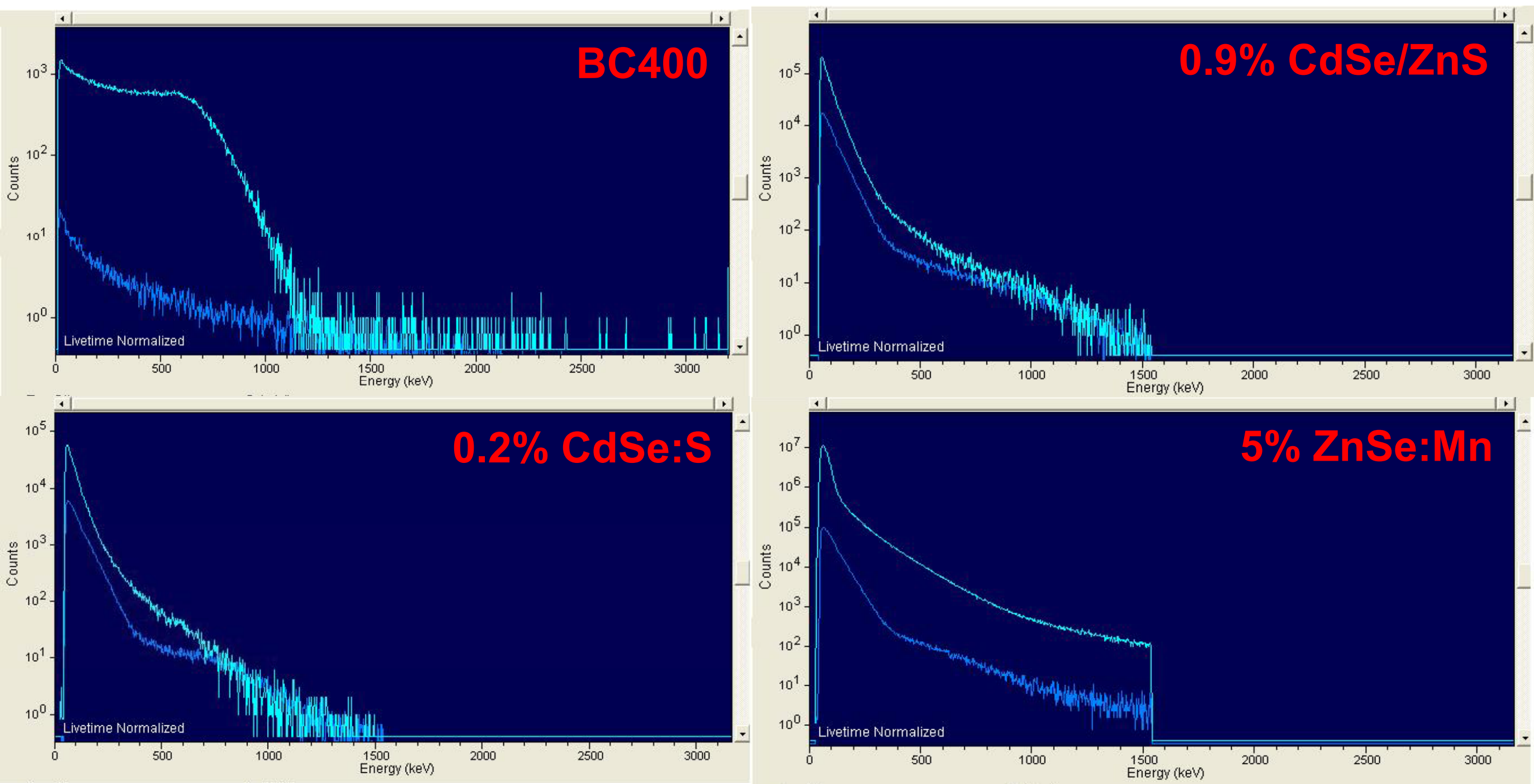

Measured Spectra with and without a $31.9-\mu \mathrm{Ci}{ }^{137} \mathrm{Cs}$ Source. 


\section{Results}

\section{- Solid Nanoparticle detector}

\begin{tabular}{|lllll|}
\hline & \multicolumn{4}{l|}{ Count Rate versus Source (cps) } \\
& & $2.8 \%$ & $1.4 \%$ & \\
Source & Intensity & CdSe/ZnS & CdSe/ZnS & BC400 \\
& $(\mu \mathrm{Ci})$ & $(\mathrm{cps})$ & $(\mathrm{cps})$ & $(\mathrm{cps})$ \\
& & $16 \mathrm{~mm} \mathrm{D}$ & $16 \mathrm{~mm} \mathrm{D}$ & $12.5 \mathrm{~mm} \mathrm{D}$ \\
& & $\times 4 \mathrm{~mm} \mathrm{~L}$ & $\times 4 \mathrm{~mm} \mathrm{~L}$ & $\times 19 \mathrm{~mm} \mathrm{~L}$ \\
Background & & 1.63 & 1.29 & 1.27 \\
${ }^{60}$ Co $(4 \mathrm{~cm})$ & 3.78 & 23.74 & 18.09 & \\
${ }^{137} \mathrm{Cs}(4 \mathrm{~cm})$ & 31.9 & 12.69 & 20.72 & 170.22 \\
${ }^{137} \mathrm{Cs}(8 \mathrm{~cm})$ & 31.9 & 9.29 & 10.54 & \\
${ }^{241} \mathrm{Am}(4 \mathrm{~cm})$ & 9.09 & 0.2 & 2.4 & \\
& & & & \\
\hline
\end{tabular}

BC400 and Nanodetector performance comparisons. 


\section{Results - Solid Nanoparticle detector}

\begin{tabular}{|c|c|c|c|c|c|c|c|c|c|c|}
\hline \multirow[b]{2}{*}{ Detector } & \multicolumn{2}{|c|}{ Detector } & \multicolumn{2}{|c|}{ Properties } & \multirow[b]{2}{*}{$\begin{array}{c}\text { Comment } \\
\text { Source Intensity -> } \\
\text { Source Distance -> }\end{array}$} & \multicolumn{5}{|c|}{ Count Rate with Source (Counts/s) } \\
\hline & Nanoparticle & Type & Volume & Concentration & & $\begin{array}{r}{ }^{241} \mathrm{Am} \\
9.09 \mu \mathrm{Ci} \\
4 \mathrm{~cm} \\
\end{array}$ & $\begin{array}{r}{ }^{137} \mathrm{Cs} \\
31.9 \mu \mathrm{Ci} \\
4 \mathrm{~cm} \\
\end{array}$ & $\begin{array}{r}{ }^{137} \mathrm{Cs} \\
31.9 \mu \mathrm{Ci} \\
8 \mathrm{~cm} \\
\end{array}$ & $\begin{array}{r}{ }^{60} \mathrm{Co} \\
3.78 \mu \mathrm{Ci} \\
4 \mathrm{~cm} \\
\end{array}$ & Background \\
\hline Detector 1 & CdSe/ZnS & Core Shell & $1 \mathrm{cc}$ & $1.40 \%$ & epoxide-amine polymer & 2.4 & 20.72 & 10.54 & 18.09 & 1.29 \\
\hline Detector 2 & $\mathrm{CdSe} / \mathrm{ZnS}$ & Core Shell & $1 \mathrm{cc}$ & $2.80 \%$ & epoxide-amine polymer & 0.2 & 12.69 & 9.29 & 23.74 & 1.63 \\
\hline Detector 3 & CdSe:S & $\begin{array}{c}\text { Quantum } \\
\text { Dot }\end{array}$ & $1 \mathrm{cc}$ & $0.20 \%$ & epoxide-amine polymer & 0.07 & 16.47 & 11.57 & 16.64 & 3.01 \\
\hline Detector 4 & $\mathrm{CdTe} / \mathrm{ZnS}$ & Core Shell & $1 \mathrm{cc}$ & $0.01 \%$ & & & & & & \\
\hline Detector 5 & CdTe/ZnS & Core Shell & $1 \mathrm{cc}$ & $0.05 \%$ & & & & & & \\
\hline Detector 6 & CdTe/ZnS & Core Shell & $1 \mathrm{cc}$ & $0.11 \%$ & & & & & & \\
\hline Detector 7 & $\mathrm{CdTe} / \mathrm{ZnS}$ & Core Shell & $1 \mathrm{cc}$ & $0.43 \%$ & & & & & & \\
\hline Detector 8 & $\mathrm{CdTe} / \mathrm{ZnS}$ & Core Shell & $1 \mathrm{cc}$ & $0.90 \%$ & & 0.09 & 52.95 & 16.69 & 33.74 & 7.34 \\
\hline Detector 9 & CdTe/ZnS & Core Shell & $1 \mathrm{cc}$ & $2 \%$ & & & & & & 54.13 \\
\hline Detector 10 & ZnSe:Mn & $\begin{array}{c}\text { Quantum } \\
\text { Dot }\end{array}$ & $1 \mathrm{cc}$ & $1 \%$ & polystyrene matrix & 0.07 & 64.82 & 20.7 & 49.4 & 2.59 \\
\hline Detector 11 & ZnSe:Mn & $\begin{array}{c}\text { Quantum } \\
\text { Dot }\end{array}$ & $1 \mathrm{cc}$ & $2 \%$ & polystyrene matrix & 3.97 & 61.46 & 25.76 & 50.68 & 2.64 \\
\hline Detector 12 & ZnSe:Mn & $\begin{array}{c}\text { Quantum } \\
\text { Dot }\end{array}$ & $1 \mathrm{cc}$ & $5 \%$ & polystyrene matrix & 0.05 & 683.39 & 471.66 & 20.88 & 9.25 \\
\hline Detector 13 & $\mathrm{D} 1$ & Core Shell & $<1 \mathrm{cc}$ & $0.90 \%$ & Surfactant & & & & & \\
\hline Detector 14 & $\mathrm{D} 2$ & Core Shell & $<1 \mathrm{cc}$ & $0.43 \%$ & Surfactant & & & & & \\
\hline Detector 15 & D3 & Core Shell & $<1 \mathrm{cc}$ & $0.11 \%$ & Surfactant & & & & & \\
\hline Detector 16 & D4 & Core Shell & $<1 \mathrm{cc}$ & $0.05 \%$ & Surfactant & & & & & \\
\hline Detector 17 & D5 & Core Shell & $<1 \mathrm{cc}$ & $0.01 \%$ & Surfactant & & & & & \\
\hline Detector 18 & D6 & Core Shell & $<1 \mathrm{cc}$ & $0.90 \%$ & Surfactant & & & & & \\
\hline Detector 19 & BC400 & & $1 \mathrm{cc}$ & $0 \%$ & & & 170.22 & & & 1.27 \\
\hline
\end{tabular}

Nevada National Security Site

Managed and Operated by National Security Technologies, LLC
$-25-$

Vision - Service - Partnership 


\section{Discussion}

\section{Initial results indicate that $\mathrm{BC} 400$ performs better:}

- This is our first run for nanoparticle detectors

- The nanoparticle detectors do demonstrate an ability to distinguish different $y$-ray energies and sources

- They also demonstrate a neutron response

- Efficiency increases with increasing nanoparticle content

- Spectroscopic fidelity increases with decreasing nanoparticle content 


\section{Summary}

Nanocomposite detectors are cheap, easy to fabricate, and respond to nuclear radiation. We have established correlations between energy spectra $y$-ray energy. We have not observed significant improvement compared to BC400, but need more work to determine how best to obtain isotopic correlations and to optimize light yield.

Recommendations for future direction

- Refine MCNPX model to improve match to experimental data

- Adjust MCNPX parameters to improve detector performance

- Make assessment of modeling results for future detector developments 


\section{References}

1. Del Sesto, R. E., E. A. McKigney, D. W. Cooke, R. E. Muenchausen, K. C. Ott, R. D. Gilbertson, T. M. McCleskey, M. Bacrania, L. G. Jacobsohn, A. K. Burrell, B. L. Bennett, S. C. Sitarz, J. F. Smith, 2007. Development of Nanocomposite Scintillators. LALP-07-030 Spring 2007. Los Alamos National Laboratory, N. M.

2. Letant, S. E. and T. F. Wang, March 2006. Study of Porous Glass Doped with Quantum Dots or Laser Dyes under Alpha Irradiation. Applied Physics Letters, 103110.

3. Guss P., Guise R., Reed M., Mukhopadhyay S., and Yuan D., "Nanostructured LaF 3 :Ce Quantum Dot Nuclear Radiation Detector." 2010 ANS Winter Meeting and Nuclear Technology Expo, (DOE/NV/25946--1013). Las Vegas, NV, November 7-11, 2010.

4. Guss P., S. Mukhopadhyay, and D. Yuan, 2010. Nanostructured Lanthanum Halides and $\mathrm{CeBr}_{3}$ for Nuclear Radiation Detection. ANS NV Topical Meeting. April 18-23, 2010 . Las Vegas, NV.

5. Guss P., M. Reed, D. Yuan, D. Beller, C. Contreras, M. Cutler, 2010. Comparison of $\mathrm{CeBr}_{3}$ with $\mathrm{LaBr}_{3}: \mathrm{Ce}, \mathrm{LaCl}_{3}: \mathrm{Ce}$, and Nal:TI Detectors. SPIE Conference on Hard X-Ray, Gamma-Ray, and Neutron Detector Physics XII. August 1-5, 2010. San Diego, CA.

6. Guss, P., A. Reed, M. Reed, S. Mukhopadhyay, D. Yuan, M. Cutler, C. Contreras, and D. Beller, 2010. Modeling Higher Resolution Scintillators for Non-Proliferation. American Nuclear Society Annual Meeting. June 13-17, 2010. San Diego, CA, .

7. Guss, P., S. Mukhopadhyay, R. Guise, and D. Yuan, 2010. Nanostructured Lanthanum Halides and $\mathrm{CeBr}_{3}$ for Nuclear Radiation Detection. LDRD Symposium. June 9, 2010. Washington, D.C.

8. McKigney, E.A. Nanocomposite scintillators for radiation detection and nuclear spectroscopy NIM A 579 (2007) 15.

9. Walters, R. J., J. Kalkman, A. Polman, H. A. Atwater, and M. J. A. de Dood. Photoluminescence quantum efficiency of dense silicon nanocrystal ensembles in $\mathrm{SiO}_{2}$. Phys Rev B 73, (2006) 132302. 